\title{
Corrigendum to "Experimental Study of the Slit Spacing and Bed Height on the Thermal Performance of Slit-Glazed Solar Air Heater"
}

\author{
Seyed Mahdi Taheri Mousavi and Fuat Egelioglu \\ Mechanical Engineering Department, Eastern Mediterranean University, Famagusta, Northern Cyprus Mersin 10, Turkey \\ Correspondence should be addressed to Seyed Mahdi Taheri Mousavi; smahditaherim@gmail.com \\ Received 6 September 2017; Accepted 4 October 2017; Published 5 November 2017 \\ Copyright ( 2017 Seyed Mahdi Taheri Mousavi and Fuat Egelioglu. This is an open access article distributed under the Creative \\ Commons Attribution License, which permits unrestricted use, distribution, and reproduction in any medium, provided the \\ original work is properly cited.
}

In the article titled "Experimental Study of the Slit Spacing and Bed Height on the Thermal Performance of Slit-Glazed Solar Air Heater" [1], the name of the first author was given incorrectly as Seyyed Mahdi Taheri Mousavi. The author's name should have been written as Seyed Mahdi Taheri Mousavi. The revised authors' list is shown above.

\section{References}

[1] S. M. Taheri Mousavi and F. Egelioglu, "Experimental study of the slit spacing and bed height on the thermal performance of slit-glazed solar air heater," International Journal of Photoenergy, vol. 2017, Article ID 9851376, 14 pages, 2017. 

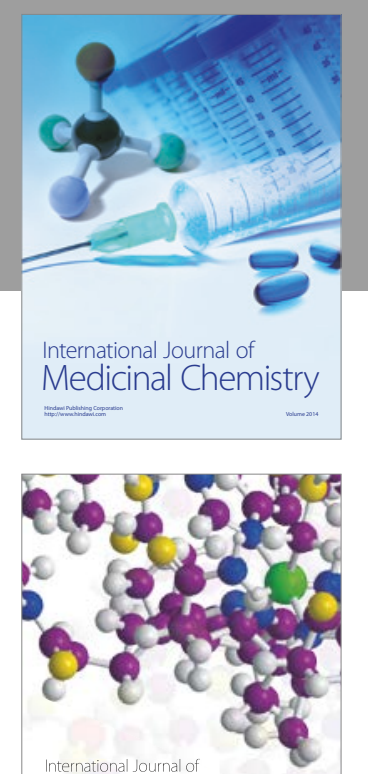

Carbohydrate Chemistry

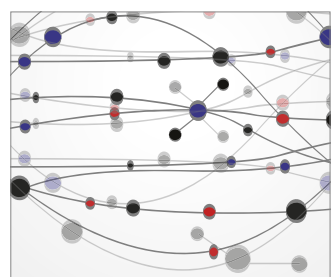

The Scientific World Journal
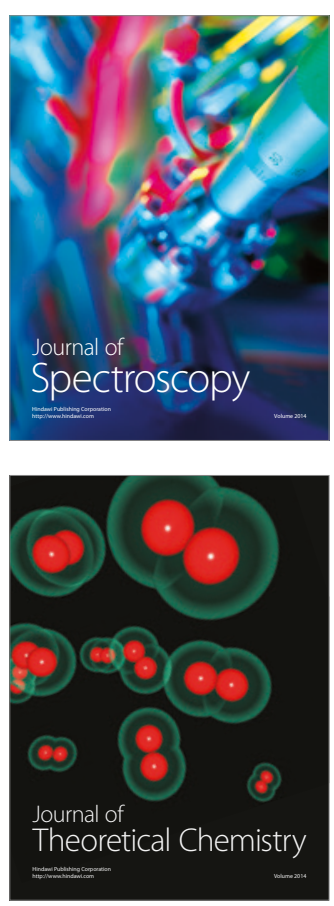
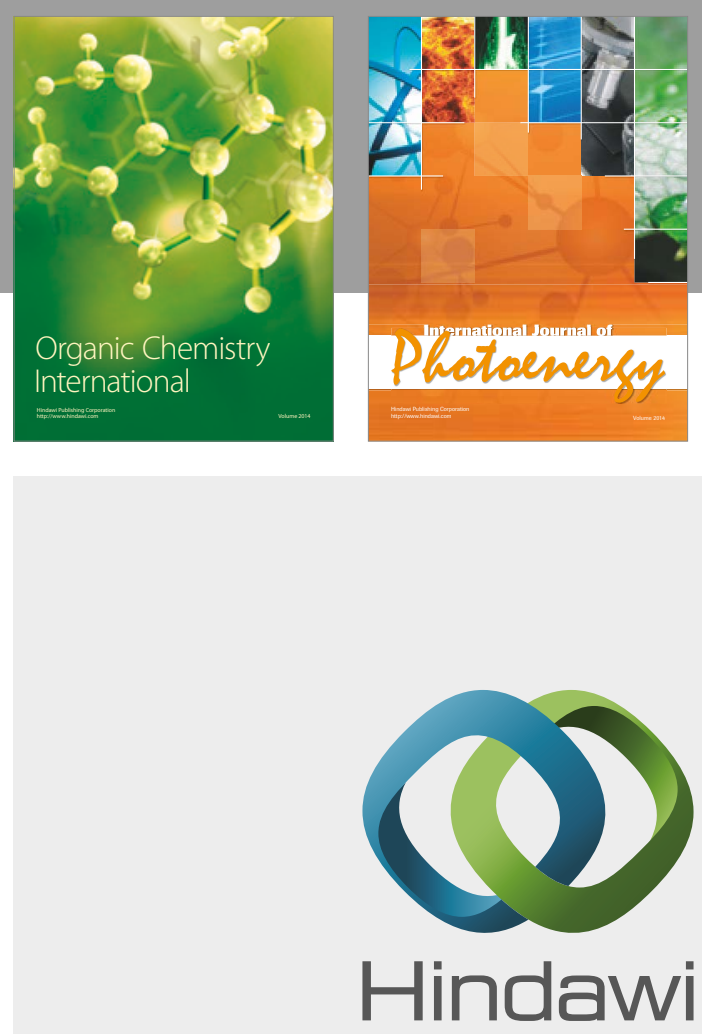

Submit your manuscripts at

https://www.hindawi.com

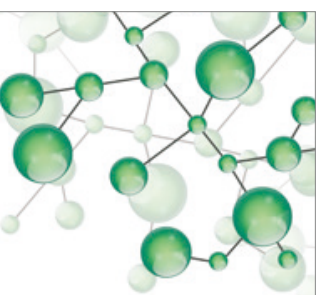

International Journal of

Inorganic Chemistry

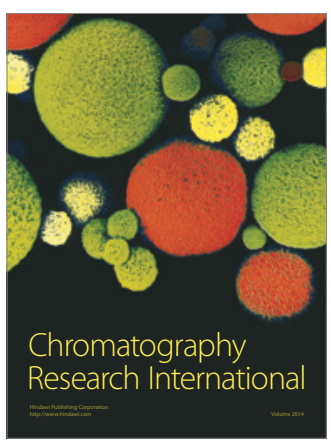

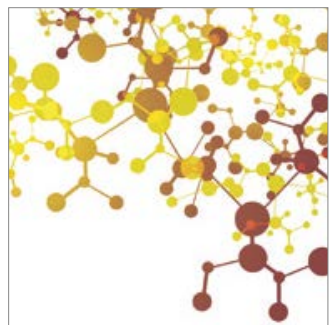

Applied Chemistry
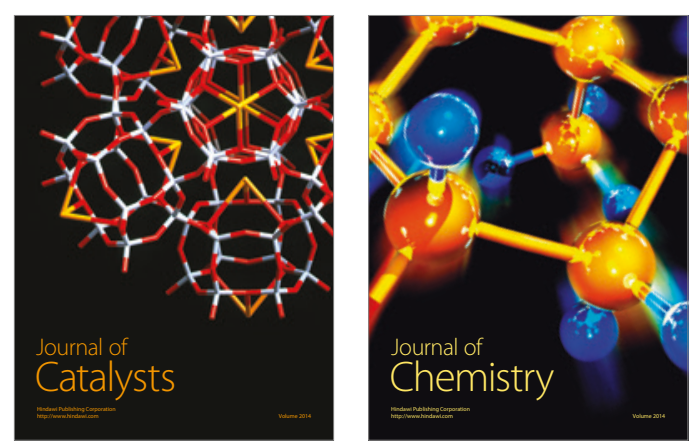
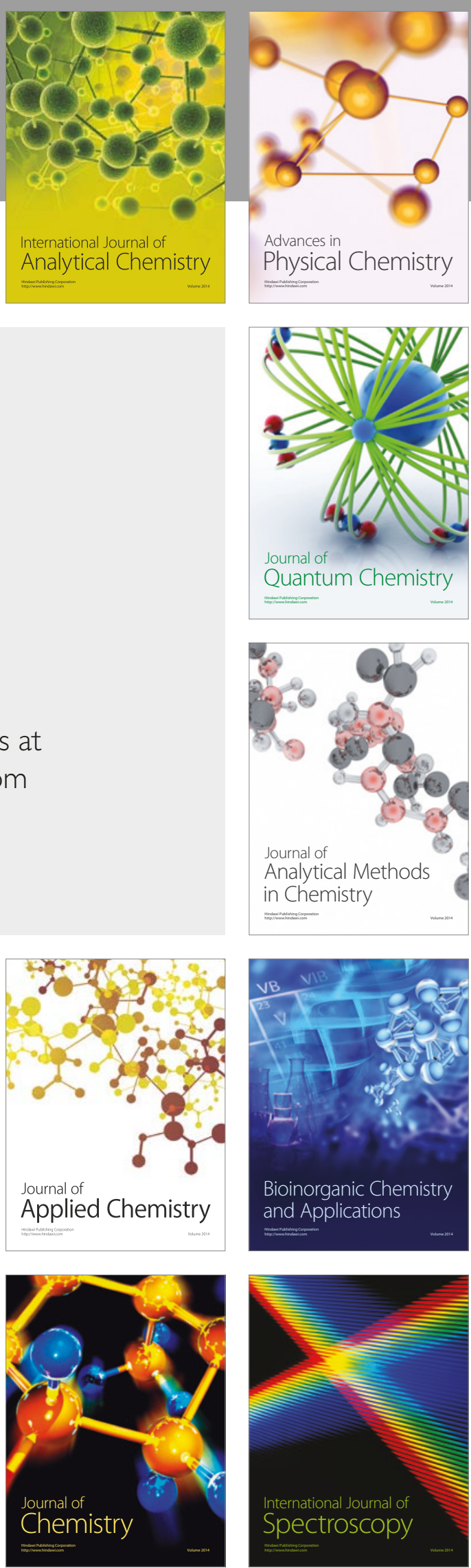